\title{
Upgrade and Organized Innovation of China's NC Generation Products: Using the NC Generation Innovation Project in Quanzhou City as A Case Study
}

\author{
Wei Feng ${ }^{1,2}$, Zhou Yuan ${ }^{2}$, Xue Lan ${ }^{2}$ \\ 1. Chinese Academy of Engineering, Beijing 100088, China \\ 2. School of Public Policy and Management, Tsinghua University, Beijing 100084, China
}

\begin{abstract}
The Numerical Control (NC) Generation Innovation Project aims to apply NC technology to the mechanical products of all industries to update and upgrade the overall installed base of manufacturing equipment, thus promoting upgrading of the industrial base. This paper takes the update and upgrade of NC equipment in Quanzhou city as a case study. Focusing on practical experience with the NC Generation Innovation Project within the framework of innovation governance, it discusses a new generation of "organized innovation" generated by the collaboration of multiple innovation participants. Through analysis and on the basis of strong demand pull from the user market and effective technology push from R\&D agencies, the NC Generation Innovation Project, by playing a "skillful deflection" role, has enabled the government to kick-start extensive market resource investment with a small amount of policy resources, to mobilize the enthusiasm of multiple innovation participants such as enterprises, R\&D institutions, intermediaries, and financial institutions and to organize many manufacturing enterprises in different industries. Using the principles of the market economy, these enterprises overcame all kinds of obstacles, actively accepting key generic technology. The result is a successful example of promoting generic technology diffusion in manufacturing industries. At the same time, this project has found existing insufficiencies in the course of summarizing the existing successful experience and has provided a decision-making basis for advancing of a broad-based manufacturing industry upgrade.
\end{abstract}

Keywords: NC generation; generic technology; technology diffusion; innovation governance; organized innovation

\section{Introduction}

Numerical control (NC) technology is a revolutionarily key generic technology to achieve mechanical product innovation in various industries. It is an integration technology that combines advanced information technology, automatic control, and mechanical manufacturing technology. The core requirement of accelerating the transformation of economic development is to optimize industrial structure, and the key to this is the upgrading and updating of products. NC technology and products (including $\mathrm{NC}$ systems and actuating devices) that is a organic integration of a generic enabling technology and mechanical products in all industries can achieve digital control of mechanical production, fundamentally improve the functionality and performance of manufacturing equipment in all industries, restore the momentum of enterprises, enhance their market competitiveness, and finally lay a solid foundation for realizing an intelligent and well-focused development of mechanical products [1-3]. The

Received date: 28 October 2016; revised date: 18 November 2016

Corresponding author: Wei Feng, Chinese Academy of Engineering and Tsinghua University, Postdoctor. Major research fields include intelligent manufacturing and strategic emerging industry development, public governance, and technology innovation diffusion. E-mail: weifengg@163.com

Funding program: CAE Major Advisory Project “Manufacturing Power Strategy” (2015-ZD-10); National Natural Science Foundation of China (L1524015, 71203117); Ministry of Education Humanities and Social Science Research Fund Project (16JDGC011); China Postdoctoral Science Fund Project (2016M601090); Subproject of the Research Center of Green Economy and Sustainable Development at Tsinghua University (20153000181)

Chinese version: Strategic Study of CAE 2016, 18 (6): 110-116

Cited item: Wei Feng et al. Upgrade and Organized Innovation of China's NC Generation Products: Using the NC Generation Innovation Project in Quanzhou City as A Case Study. Strategic Study of CAE, http://10.15302/J-SSCAE-2016.06.022 
NC Generation Mechanical Product Innovation Application Demonstration Project (also known as the NC Generation Innovation Project) is the major project of Made in China 2025, which aims to apply NC technology to mechanical production in all industries to achieve the upgrading and updating of overall manufacturing equipment. It is a successful example of generic technology diffusion, but at the same time, it faces severe difficulties and challenges and needs to be further improved and perfected.

The innovation and diffusion of generic technology refers to the whole process from the generation of new products or new technology ideas, through technology development (or import, digestion, and absorption), production, and commercialization, to industrialization. All this occurs under the guidance of the market, which based on generic technology innovation, makes its selection with enhancing industry competitiveness as the goal and with an emphasis on diffusing innovative technology among enterprises or industries [4]. Therefore, generic technology diffusion is the result of complex interactions among various organizations, including social networks and the complex relationships formed by organic connections and interactions among various innovation participants $[5,6]$. The NC Generation Innovation Project is a product innovation project for mechanical products of all industries, as well as a generic technology diffusion project for NC technology [1]. The spread and promotion of this kind of generic technology not only relates to large manufacturing enterprises, but also involves other multiple independent entities and departments along the innovation chain. However, neither the traditional "top-down" command-and-control policy model nor the market mechanism model alone can function effectively in this situation. Therefore, one of the major challenges faced by industrial innovators is how to drive and lead large manufacturing enterprises to overcome obstacles and accept applications of generic technology according to the principles of the market economy. In innovation project implementation, the enterprise is the core of the technology diffusion system. Government plays the key role of a "skillful deflector", kick-starts extensive market resource investment with a small amount of policy resources, and fully mobilizes the enthusiasm of multiple innovation participants such as colleges and universities, research institutes, industrial intermediaries, and financial institutions. Within this innovation governance framework, this multifaceted governance model encourages a new generation of "organized innovation."

Since the 1970s, new emerging problems in the social, economic, and management fields have promoted a change in public management and public administration theory $[7,8]$. The new theory, represented by the governance model proposed here, represents a public governance model of diversification, selforganization, cooperation, and ideological neutrality [9-12]. Since the 1990s, western countries' politics and economics have applied these governance concepts widely in the social and economic fields and have formulated a relatively unified definition: governance is the sum of the many ways in which a variety of public or private sector participants manage their common affairs and involves a continuous process of reconciling conflicts among various interests to take joint action $[12,13]$. Therefore, governance not only involves the public sector, but also includes the private sector; the basis of its process is not control, but coordination.

Innovation governance is the application of the concept, structure, model, etc., of governance to science and technology policy management. The aim of an effective response to government and market failures is to improve efficiency, reduce cost, optimize effective resource allocation, and encourage science and technology innovation and coordinated development of the social economy [12]. The diversity of innovation governance creates conditions for improving science and technology policy execution. In the process of promoting and applying NC technology, a major issue that China's current industrial transformation and upgrading process must solve urgently is how to perfect innovation governance with the aim of carrying out organized innovation projects around multiple departments, multiple participants, and an interdisciplinary innovation chain.

Innovation governance relates not only to the allocation of science and technology resources, but also to the construction of innovation systems and the seamless interconnection of industrial innovation chains. At present, innovation governance research is a growing field that is mainly concentrated on innovation systems and comparison of development models $[11,12]$. Research on multiple participants in innovation governance and their role in large-scale generic technology diffusion, building innovation governance systems, and enhancing innovation governance capacity is less common. In particular, case analyses and practical research on these aspects are even rarer. Therefore, under the concept of innovation governance and focused on the practical experience of the NC Generation Innovation Project, this research has selected the upgrading and updating of NC equipment in Quanzhou City as a case study. From the viewpoint of promoting NC technology diffusion and upgrading manufacturing industries, this paper discusses a new generation of "organized innovation" models generated by the synergy of multiple innovation participants, summarizes the successful experience of NC generation projects, identifies existing problems, and provides a basis for better promoting the diffusion of China's generic enabling technology and widely upgrading its manufacturing industry.

\section{Introduction and background}

\subsection{Main features of NC technology diffusion}

A review of the history of industrial structural adjustment and the process of mechanical production upgrading is shown in Fig. 1. Steam engine technology moved the machine-building industry from the age of human power into the mechanization era 


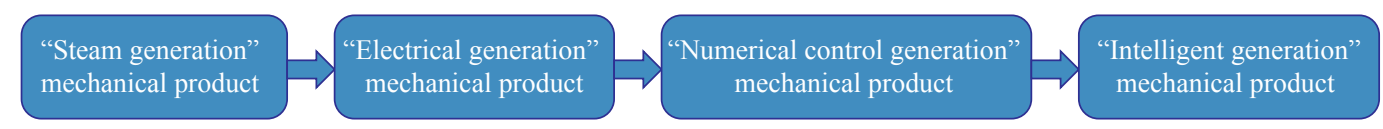

Fig. 1. Upgrading and updating of mechanical production [1].

(Industry 1.0 or mechanical generation). Electrical technology in its turn moved the machine-building industry from the mechanization age into the electrification era (Industry 2.0 or electrical generation). $\mathrm{NC}$ technology is in process of converting the machine-building industry from the electrification age into the digital era (Industry 3.0 or NC generation). Smart technology will in turn convert the machine-building industry from the digital age into the intelligent era (Industry 4.0 or intelligence generation) [1,2].

The current level of popularity of NC technology is an important indicator of the core competitiveness and overall technical development level of China's manufacturing industry. Intelligent manufacturing technology is based on mechanical production digitization and the application of a new generation of information technology to key links in the manufacturing system. This technology has certain autonomous abilities such as perception, learning, analysis, decision-making, communication, coordination, and control and can dynamically adapt to changes in the manufacturing environment. Hence, optimal objectives are achieved, and intelligent generation is realized.

Therefore, NC generation product innovation is the foundation of intelligent manufacturing. Given the current national conditions of China's industrial development (late start, poor foundation, and uneven regional and industry development), the main task of current manufacturing industry development is to achieve certain strategic objectives. This task can be summarized as Industry 2.0: make up missed lessons; Industry 3.0: popularize; Industry 4.0: pilot demonstration. Against this background, China has launched the NC Generation Innovation Project as part of the 12th Five-Year Plan.

In history, there have been two main methods of mechanical product evolution and innovation [1,2]. One is the innovation of a working principle or working device; this has fundamental and disruptive characteristics and is rare, but particularly important. The other is innovation in the drive and control systems of mechanical movement. Traditional mechanical products normally include a power device, a transmission device, and a working device (Fig. 2). NC as applied to a mechanical product is an innovation in the drive and control systems that generate its movement (Fig. 3).

$\mathrm{NC}$ innovation in drives and control systems has both distinct characteristics and essential laws. It can be widely applied to all kinds of mechanical products, leading to upgrades and updates of other mechanical products and a profound change in the manufacturing industries. NC is an effective way to achieve mechanical product innovation. Its core technology has two aspects [1]: One is that a computer control system is used to control mechanical motion and the working process; the other is that a servo

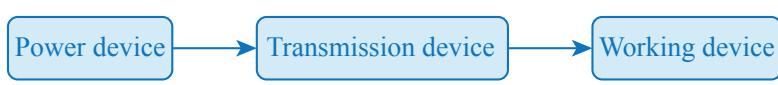

Fig. 2. Structure of a traditional mechanical product.

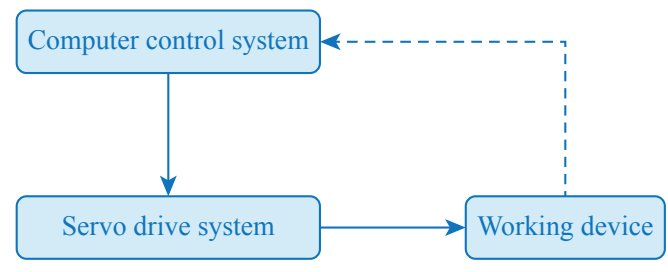

Fig. 3. Structure of an NC mechanical product.

motor drive system is used to replace traditional power and transmission devices. NC technology, combined with advanced information technology, automatic control, and mechanical manufacturing technology, can make fundamental changes in the implication and performance of mechanical products. It is a typical generic technology involved in mechanical product innovation.

Generic innovation technology is a kind of technology that can be widely used in multiple industries, has a deep influence on them, and is at the pre-competitive stage [5]. From the viewpoint of technical attributes, generic innovation technology is at the pre-competitive stage, but is the common technology platform of proprietary technology in various enterprises. From the viewpoint of industry attributes, generic innovation technology can drive research and development into proprietary technology in multiple enterprises in related industrial fields, encourage technological progress and breakthroughs in multiple related industrial clusters, and improve the comprehensive economic and social benefits of related industrial sectors.

As a typical generic innovation technology, NC technology stands somewhere between basic research and commercial development. It has dual attributes pertaining to both technology and industry. Therefore, its features can be analyzed from both technological and economic perspectives [14-16]. From a technological perspective, $\mathrm{NC}$ technology has the following features. (1) Fundamental importance: NC technology provides the technical principles and the basic method for subsequent development of NC mechanical products, directly influences and constrains the research and development of mechanical products, and provides the foundation for commercialization and marketing of technical products. In the NC technology diffusion process, because this technology must be combined with various working devices that are multitudinous and widespread, it is very important to provide individually customized technology service and development according to the process requirements of different 
working devices. (2) Relevance: NC technology is involved in different mechanical products in multiple industrial sectors and supports product performance jointly with other technological participants. The range of related products is wide, but technology generality is a strong common factor. Hence, the stability and reliability of $\mathrm{NC}$ technology has a significant influence on its diffusion. (3) Openness: NC technology provides a public platform for the subsequent technological development of related enterprises. Its results can be widely used in related enterprises and industries. Therefore, in the diffusion process, the openness of a technology should also meet certain requirements.

From the economic point of view, NC technology has the following features $[4,5]$. (1) Economic externality: NC technology can drive the progress and breakthrough of mechanical equipment in other related industries. NC technological achievements can easily overflow into relevant sectors and industrial domains, bringing corresponding economic benefits to these sectors and domains. (2) Potential of economic benefits: NC technology is a pre-competitive technology; its value can be realized only by combining it with other specialized manufacturing equipment. Hence, its economic benefits are potential; real economic benefits can be generated only when manufacturing equipment for exclusive use is developed based on it and comes into being.

In summary, as a pre-competitive technology standing between basic and applied research, NC technology occupies a key fundamental position in the whole mechanical product innovation chain and the industry value chain of "science, technology, production." Its effective provision can improve the ability of manufacturing enterprises to achieve technological innovation, reduce the technical risk of subsequent applied research and development in enterprises, and be the source of core competitiveness in the enterprise. At the same time, because NC technology has the characteristics of a "quasi-public good" and the potential for economic benefits, technological innovation activities involving $\mathrm{NC}$ technology become more complex and risky. A single participant in technological innovation would find it difficult to undertake development of $\mathrm{NC}$ technology and products and the other activities in the diffusion process, but does not need to do so independently. For this reason, interactive cooperation between relevant innovation participants should be strengthened because they will jointly promote innovation and diffusion of NC technology and products.

\subsection{Implementation outline of the NC Generation Innovation Project in the 12th Five-Year Plan}

During the 12th Five-Year Plan period, the NC Generation Innovation Project constitutes a breakthrough for key techniques such as NC mechanical equipment design, specialized control, and process optimization. As specialized design tools, control systems, and process software appear, they are comprehensively applied in textile machinery, printing and packaging machinery, light industrial machinery, building materials, plastics, and other industries, achieving a series of goals.

First, large quantities of key $\mathrm{NC}$ equipment and a number of industry-leading products are developed. This significantly enhances the support and service ability of NC technology to improve enterprise core competitiveness, accelerate the transformation and upgrading of manufacturing industries, promote development of high-end manufacturing, and strengthen local pillar industries. Second, application of NC technology and products and equipment upgrades in related industries are promoted. Combined with a regional development strategy, demonstration projects have been carried out in key industrial areas such as the Yangtze River delta, the Pearl River delta, the southern part of Fujian Province, and the midwestern region of China, improving the capability for independent innovation of mechanical products and the added value of products in these areas. Third, the application service and training system for NC technology and products must be perfected by cultivating groups of talented designers, promoting the innovation and after-sale service capabilities of China's mechanical equipment manufacturing enterprises, achieving standardization of NC technology and product application, and effectively promoting scientific and technological progress and upgrading of the machine-building industry. According to incomplete statistics, through implementation of innovation projects, the China's NC industry has developed more than 150 kinds of special computer numerical control (CNC) systems and functional components and more than 200 kinds of $\mathrm{NC}$ equipment, has produced more than 220000 sets and more than $70 \mathrm{NC}$ production lines for demonstration applications, and has completed more than 20000 people of professional staff training.

Since project implementation over the past five years, organized innovation has been implemented through the technical route described as "enterprise as main body, and market as guidance." More than 10 provincial governments have made concrete implementation plans, driving more than 1 billion yuan of special investment funds at all levels of government. Enterprises have invested more than 5 billion yuan and financial and social capital sources more than 10 billion yuan. This is a typical demonstration and success story of the combined efforts of production, academia, research, finance, and governments.

\section{Case study}

In June 2016, a national NC generation innovation application project site work meeting was held in Quanzhou City. In recent years, this city has actively implemented the NC Generation Innovation Project, achieving remarkable results. The machinery and equipment industry of Quanzhou City has reached the 100 billion yuan level. This city has developed more than 100 kinds of various types of $\mathrm{NC}$ equipment, popularized and applied more than 2000 domestic NC systems, cumulatively driving 
an increase in total R\&D investment by $30 \%$. Nearly 1000 enterprises have applied NC technology and products, on average reducing labor costs by $20 \%-30 \%$, shortening product development cycles by $20 \%$, and improving production efficiency by $20 \%$. During implementation of the NC Generation Innovation Project in Quanzhou City, full scope was given to the model of "enterprise as main body, and market as guidance." In this model, government actively transforms the mode of governance and plays a guiding role, whereas colleges and universities, research institutes, and financial institutions jointly play a supporting role. This case study has successfully implemented an organized innovation project using these innovation governance ideas.

\subsection{Collaboration in "organized innovation" by multiple innovation participants}

3.1.1 Government transforms its governance model and actively plays a guiding role

The government mainly plays the role of improving resource allocation efficiency, compensating for market failures, and providing public goods in the market economy [17,18]. Generic industrial technology is the foundation of proprietary and application technologies in enterprises. NC technology has an exceptional influence on enterprise development and industrial upgrading, and therefore government can play an important role in NC technology diffusion.

A key generic technology has a significant influence on the whole national economy. Breakthroughs in such a technology can drive technology upgrades in multiple industries, with obvious economic and social benefits. NC technology is a typical key generic technology. In the course of implementing the NC Generation Innovation Project, the function of the Quanzhou government has been based on the combination of partial administration order to play an active role in establishing a development and diffusion platform for $\mathrm{NC}$ technology and products and, through generous support for research and diffusion of pre-competitive generic technology and establishment of efficient intermediary service systems, to promote the upgrade and improvement of the whole technological system. The Quanzhou government innovates management mechanisms, adopts different organizational forms to guide the diffusion and transformation of NC technology, coordinates and balances the interests of the various parties in the main entities involved in cooperation and development, attracts multi-party participation, and enables local small and medium-sized enterprises to acquire NC technology quickly and at low cost. On this basis, combined with process requirements, the government carries out the development of special manufacturing equipment, promoting overall progress through NC technology diffusion and enhancing the competitive advantage of manufacturing. Local government has spent much fiscal capital to introduce and set up more than 10 scientific research institutes and universities, including the Quanzhou-HUST
Intelligent Manufacturing Future; the Quanzhou Institute of Equipment Manufacturing Haixi Institutes, Chinese Academy of Sciences; State Key Laboratory of Robotics and System, Harbin Institute of Technology; Xiamen University; and Fuzhou University. Government has then encouraged these entities to participate in technology diffusion and has promoted frequent interaction and close integration between technical service platforms and enterprises, from one-time corporate subsidies for technical renovation to purchasing generic industrial technical services from technical service platforms, then transferring them to small and medium-sized enterprises at low cost to promote their application. These activities have accelerated the pace of transformation and upgrading of the Quanzhou manufacturing industry, have established the Quanzhou "NC generation" industry alliance among enterprises involved in machine building, spare parts production, and system integration and application, have established an operating mechanism for collaborative innovation and win-win project outcomes, and have achieved a match between innovation resources and industrial transformation and upgrading needs.

3.1.2 Enterprises promote technology diffusion and achieve industrial upgrading through demand

Transformation of scientific and technological achievements is a relay race. The first leg is the output of research and development. If a research project does not match the demands of industrial development, the output results have no potential application market, and transformation of these achievements is out of the question. For the manufacturing industry, which is in the midst of transformations and upgrades, this means that scientific research activities must be closely aligned with enterprise development needs.

In the process of implementing the NC Generation Innovation Project in Quanzhou City, enterprises have played a significant role, selectively strengthening industry demand to provide guidance and effectively raising the equipment technology level of manufacturing industry. Local key enterprises have engaged in dialogue with related domain experts through exchange meetings, training sessions, and many other forms to achieve close alignment. Quanzhou enterprises have a huge demand for $\mathrm{NC}$ technology, and by collecting technical requirements from thousands of enterprises, they have carried out a comprehensive study and demonstration of the NC technology demands of key industries. Then they have developed NC technology and promoted product application in high-demand industries such as textiles, shoes, and clothing, construction materials, and machine tools and robots. One hundred demonstration projects and 100 demonstration enterprises have been certified by the relevant department. Local enterprises have cooperated with technical experts and the innovation team to carry out joint research through industry-university-institute cooperation, open tendering, and other approaches to solve common key technical problems in industry. The results have been to advance industrialization and 
promote R\&D and application of $\mathrm{NC}$ equipment in equipment manufacturing enterprises and labor-intensive companies. At present, hundreds of equipment manufacturing cluster enterprises and equipment application companies are involved in the pilot demonstration of NC technology innovation application in Quanzhou City, and complete diffusion and application of 423 robots, 1834 sets of $3 \mathrm{C}$ drilling and tapping centers, and 2239 sets of $\mathrm{NC}$ equipment.

3.1.3 Multiple innovation participants take full advantage of synergistic effects and ensure effective supply

Technology innovation and diffusion are not ideal linear processes, but result from interaction and feedback among all elements of a unified system [14,19-22]. Because NC technology diffusion is associated with different departments and the technological base of different industries, it has higher requirements for R\&D investment, technical reserve capacity, human resources, and organization management. This process, as the result of complex interactions among innovation participants, needs coordination and full involvement to achieve risk- and results-sharing.

Without a doubt, Quanzhou local enterprises have been the core participants. Without the direct participation of enterprises, it is difficult for NC technology innovation to produce real economic benefits. All kinds of public technology service platforms also play an important role. If enterprises are carrying out NC equipment $R \& D$ and innovation, collaboration with multiple other participants such as scientific research institutions, universities, and other intermediaries is an inseparable component. In Quanzhou City, in an effort to achieve the stated goals, various innovation participants that were engaged in $\mathrm{CNC}$ technology diffusion frequently exchanged information and resources, and cooperated with other participants, leading to a large number of industry-university-institute cooperative application demonstration projects and innovation achievements. The QuanzhouHUST Intelligent Manufacturing Future; the Quanzhou Institute of Equipment Manufacturing Haixi Institutes, Chinese Academy of Sciences Research Institute; the State Key Laboratory of Robotics and System, Harbin Institute of Technology; and enterprises such as J-Tech CNC Technology Co., Ltd., Haitian Plastics Machinery Group Co., Ltd., and Yuding Machinery Co., Ltd. have generated actual results for development and application of multi-spindle and multichannel NC machine tools, bending machine control systems, intelligent robots, and many others. In addition, various $\mathrm{NC}$ technology programs carried out by universities such as Huaqiao and Fuzhou Universities in cooperation with enterprises have also reached the laboratory testing, pilot plant testing, industrial application, and marketing stages. In the promotion and application of $\mathrm{NC}$ mechanical products, in addition to $\mathrm{NC}$ technology support provided by universities and research institutions, financial institutions and various kinds of funds have provided financial support, industrial intermediary departments have provided information support and coordination services, education and training departments have provided innovative talent, and science and technology departments have provided guarantees such as system construction, policy intervention, and legal consultation. Practical experience has proved that only by including all kinds of innovation participants such as the private sector (e.g., enterprises), the public sector (e.g., government, public scientific and research institutions, higher education institutions), and market intermediary organizations (e.g., industry associations), is it possible to strengthen synergistic coordination, build scientific and reasonable operating specifications, develop mutually beneficial and win-win industrial generic technology support systems, effectively avoid various risks in the process of implementing NC generation innovation, and ensure the orderly advance and functioning of R\&D and the application of NC mechanical products in the highly developed market economy in Quanzhou.

\subsection{Existing deficiencies}

In the past, finance allocation funds have been used as the main investment channel for science and technology. This financing mechanism is difficult to adapt to the development requirements of independent innovation. In the future, full advantage should be taken of all kinds of social and financial capital in the process of technology diffusion. At present, with the coordination of interests and relationships among all parties and with relevant policy encouragement, Quanzhou local financial sectors such as financial guarantees, lease financing, etc., have gradually become involved in supporting innovation and diffusion of generic technology in the manufacturing industry. Funds established by multiple local non-governmental organizations have also provided financial assistance. However, according to the survey, when upgrading and updating $\mathrm{NC}$ equipment in Quanzhou manufacturing enterprises, more than $80 \%$ of enterprises relied on their own funds or on bank loans to finance equipment upgrades. Relying on this one way of financing has had a limiting influence on the intensity and scope of NC technology diffusion. Therefore, a further stage, involving multiple approaches such as soft loans, lease financing, and risk compensation, will be required in the future, thus reducing investment and financing risk when upgrading NC equipment, broadening the scope of available financing channels, and encouraging more financial and social capital input to move into the real economy, effectively increasing the supply of funds for technological transformation.

In addition, in the process of generic technology innovation and diffusion, the enterprise is not only the main body of technology application, but also the main body of technological innovation. NC technology is generic technology, but the combi- 
nation of NC technology and the massive and extensive mechanical product requirements of different industries is the second wave of NC technology development and application. To perform secondary development to meet the requirements of tens of thousands of enterprises, even the combined forces of colleges, universities, and research institutes are not enough, but must be supplemented by the technical capabilities of the thousands of enterprises themselves. This situation has been confirmed by field investigations. The primary technology source for NC transformation of local enterprise equipment was the enterprise itself, rather than scientific research institutes and universities. At the same time, local technical service institutions for customization and marketing are rare in Quanzhou, and therefore it is urgent to carry out a large-scale training project to develop skilled talent in enterprises and to help foster a number of marketoriented professional technology service companies.

\section{Conclusions}

$\mathrm{NC}$ is an effective approach to mechanical product innovation. The organic integration of $\mathrm{NC}$ technology and products into mechanical equipment in all industries, achieving digital control of mechanical equipment, can fundamentally improve functionality and performance and lay a foundation for finally achieving intelligent upgrades of mechanical equipment. Therefore, the achievement of NC technology diffusion over a wide range of China's manufacturing industry has the significance of serving as a link between past and future. For a long time, China's macro management of science and technology focused on scientific research management of the $R \& D$ chain, but the traditional "topdown" command-and-control policy has not adapted well to the new development situation. This is a fundamental problem that China's current industrial upgrade should solve. For example, within a framework of innovation governance, how to carry out organized innovation projects involving multiple departments, multiple participants, and an interdisciplinary innovation chain and how to mobilize the massive and extensive enterprises of China's manufacturing industry in line with the principles of a market economy to overcome various obstacles and actively accept a key generic technology. This paper is based on the practical experience of the NC Generation Innovation Project through a specific analysis of the upgrading and updating of NC equipment in Quanzhou. It explores the cooperative relationships among multiple innovation participants within the framework of a new type of innovation governance process for organized innovation. Through analysis, it explains that the NC Generation Innovation Project is a model for success in promoting generic technology diffusion in the manufacturing industry. By playing the role of a "skillful deflector", based on the pull of strong demand from the user market and the drive of effective technology coming from R\&D institutions, government has kick-started extensive market resource investment with a small amount of pol- icy resources. Finally, although deficiencies were found during the process of summarizing the existing successful experience, these provide a decision-making basis for better promotion of $\mathrm{NC}$ technology diffusion and a large-scale upgrade of the manufacturing industry.

\section{References}

[1] Zhou J, Shao X Y, Zhou Y H. Strategic significance and technical route of "NC generation" mechanical product innovation project [J]. China Mechanical Engineering, 2012, 23 (1): 1-6. Chinese.

[2] Zhou J. Digitalization and intelligentization of manufacturing industry [J]. Advances in Manufacturing, 2013, 1 (1): 1-7.

[3] Wan G. Implementing the spirit of national science \& technology innovation conference and promoting the $\mathrm{NC}$ generation innovation project [R]. Quanzhou: the National NC Generation Innovative Application Project Meeting, 2016. Chinese.

[4] Li J Z. Supply and diffusion model selection of generic technology [J]. Science of Science and Management of S\&T, 2011, 32 (10): 5-12. Chinese.

[5] Fu J J. The theory of technological innovation [M]. Beijing: Tsinghua University Press, 1998. Chinese.

[6] Fan X H, Chen H R, Yang S G. Analysis the connotation of technology transfer and related conception [J]. Science and Technology Management Research, 2000 (6): 44-46. Chinese.

[7] Horbach J. Determinants of environmental innovation -New evidence from German panel data sources [J]. Research Policy, 2008, 37 (1): 163-173.

[8] Pelkonen A. The problem of integrated innovation policy: Analyzing the governing role of the science and technology policy council of Finland [J]. Science and Public Policy, 2006, 33 (9): 669-680.

[9] Trianni A, Cagno E, Worrell E. Innovation and adoption of energy efficient technologies: An exploratory analysis of Italian primary metal manufacturing SMEs [J]. Energy Policy, 2013, 61: 430-440.

[10] Lu M, Ren S C, You J X. Public governance and science and technology innovation management: An integrated framework [J]. Science of Science and Management of S\&T, 2010, 31 (6): 71-79. Chinese.

[11] Wang H X, Duan X M. Review of latest development of public science and technology management theory $[\mathrm{J}]$. Science of Science and Management of S \&T, 2008, 29 (6): 108-113. Chinese.

[12] Yang J M, Feng J W. China's direction of S\&T macro management reform from the prospect of innovation governance $[\mathrm{J}]$. Science \& Technology Progress and Policy, 2013, 30 (3): 99-103. Chinese.

[13] Sun F Q. Accelerate the transformation from technological management to innovating governance [J]. Scientific Development, 2014 (10): 64-67. Chinese.

[14] Zhang X, Shen L, Chan S Y. The diffusion of solar energy use in HK: What are the barriers [J]. Energy Policy, 2012 (41): 241-249. Chinese.

[15] Dou L C, Li G P. A domestic empirical study of late mover advantage-Based on the analysis of technology innovation diffusion angle [J]. Economic Science, 2004 (4): 27-32. Chinese.

[16] Robertson P, Patel P. New wine in old bottles: Technological diffusion in developed economies [J]. Research Policy, 2007, 36 (5): $708-721$. 
[17] Wang S Z. Governance theory and its applicability in China [D] Hangzhou: Zhejiang University (Doctoral dissertation), 2009. Chinese.

[18] Zhou Y, Xu G, Tim M, et al. How do public demonstration projects promote green-manufacturing technologies - A case study from China [J]. Sustainable Development. 2015, 23: 217-231.

[19] Arora S K, Foley R W, Youtie J, et al. Drivers of technology adoption-The case of nanomaterials in building construction [J] Technological Forecasting and Social Change, 2014, 87: 232-244.
[20] Liu X, Gao X. A survey analysis of low carbon technology diffusion in China's iron \& steel industry [J]. Journal of Cleaner Production, 2016 (129): 88-101.

[21] George M, Abdullahi D. Cognitive skills, innovation and technology diffusion [J]. Economic Modelling, 2013, 30 (2): 565-578.

[22] Zhou Y, Zhang H, Ding M. How public demonstration projects affect the emergence of new industries: an empirical study of electric vehicles in China [J]. Innovation Management Policy \& Practice. 2015, 15 (2): 1-23. 